\title{
O MESTRADO PROFISSIONAL NA ÁREA DE ENSINO
}

\author{
P. A. D. SILVA* e J. C. DEL PINO \\ Universidade Federal do Rio Grande do Sul - UFRGS \\ palbertasse@yahoo.com.br*
}

Submetido em 13/09/2016 - Aceito em 293/11/2016

DOI: $10.15628 /$ holos.2016.5079

\section{RESUMO}

Este trabalho traça um panorama da situação dos Mestrados Profissionais (MP) da área de Ensino no Sistema Nacional de Pós-Graduação. Por meio das ferramentas de pesquisa bibliográfica e documental, realizamos este estudo de natureza quantitativa no qual foram analisados os dados dos programas de pósgraduação em funcionamento no país. A área de Ensino criada em 2000, é a que mais possui programas de Mestrado Profissional, 56\% do total de seus programas são dessa modalidade, e os dados mostram que a procura por cursos desse tipo continua a crescer. Diante dessa expansão, verificamos o impacto da regulamentação dos Mestrados Profissionais pela Portaria CAPES/MEC no 17 de 2009, analisando as propostas de cursos novos antes e depois dessa data. Comparamos os programas acadêmicos e os profissionais da área quanto a produtividade técnica, o percentual de propostas de cursos novos e programas existentes, verificando os fatores limitantes para sua implantação e o seu desempenho nas reavaliações periódicas. Verificamos que os mestrados profissionais vêm crescendo em quantidade e qualidade, mas ainda tem menor produtividade científica em comparação com os programas acadêmicos.

\section{PROFESSIONAL MASTER IN ENSINO AREA}

\begin{abstract}
This paper presents an overview of the situation of professional masters in the Ensino area at the National Graduate System. Through bibliographical and documentary research tools, we conducted this quantitative study, in which we analyzed data from the graduate programs in Brazil. The Ensino area was established in 2000, and nowadays is the one that has most professional programs, $56 \%$ of it, and the data show that demand for such courses continues to grow. Given this expansion, we studied the impact of professional courses regulation by Ordinance CAPES /
\end{abstract}

MEC No. 17/ 2009, analyzing the proposals for new courses before and after that. We compared the academic and professionals programs by their technical productivity, percentage of proposals for new courses and programs, checking the limiting factors for its implementation and its performance in periodic reassessments. We found that the professional masters are growing in quantity and quality, but still has less scientific productivity compared to academic programs.

KEYWORDS: Professional master, Education, National Graduate System, Graduate evaluation. 


\section{INTRODUÇÃO}

\subsection{A área de Ensino}

Com o intuito de facilitar o desenvolvimento das atividades de avaliação, a Coordenação de Aperfeiçoamento de Pessoal de Nível Superior - CAPES organiza o Sistema Nacional de PósGraduação - SNPG em 3 Colégios e 9 Grandes Áreas, nas quais estão distribuídas as 48 áreas de conhecimento agregadas por critério de afinidade. A área de Ensino está inserida na Grande Área Multidisciplinar, dentro do Colégio de Ciências Exatas, Tecnológicas e Multidisciplinar.

A instituição da área de Ensino é resultado do esforço de físicos, químicos, matemáticos, biólogos, geólogos e profissionais de outras áreas das Ciências Humanas e Sociais, tais como psicólogos, filósofos, sociólogos, historiadores, pedagogos, antropólogos, etc., que nas últimas décadas dedicaram-se de forma inter/multidisciplinar ao estudo de questões relacionadas ao ensino e aprendizagem. De acordo com o Documento da Área de Ensino de Ciências e Matemática - ano 2009 da Coordenação de Aperfeiçoamento de Pessoal de Nível Superior [CAPES] (2009), os caminhos para a consolidação da área remontam ao início da década de 1960, quando se esboçava uma preocupação mais sistemática de cientistas, grupos de pesquisa e instituições quanto às questões relativas ao ensino e aprendizagem em suas áreas de atuação. Um dos marcos para o início da consolidação de grupos de pesquisa e formação de professores e a formação da própria área de Ensino de Ciências e Matemática no país, foi o Subprograma Educação para a Ciência do Programa de Apoio ao desenvolvimento científico e tecnológico (SPEC/PADCT), realizado entre 1983 e 1997, que contou com o apoio da Coordenação e Aperfeiçoamento de Pessoal de Nível Superior (CAPES), do Ministério da Educação (MEC) e do Banco Mundial (BIRD). Seus principais objetivos foram ampliar, melhorar e consolidar a competência pedagógica no âmbito de universidades, centros de pesquisa e outras instituições através da constituição de grupos emergentes e ou fortalecimento de grupos já constituídos, considerados relevantes ao fomento e implementação de uma política de incentivo à pesquisa e melhoria da qualidade dos ensinos de Ciências e Matemática no Brasil, em nível fundamental e médio (Documento Básico SPEC/ PADCT/CAPES, 1990).

Ainda de acordo com o Documento da Área de Ensino de Ciências e Matemática - ano 2009 (CAPES, 2009), a partir de 1980 surgem eventos nacionais específicos com a finalidade de apresentar e discutir pesquisas produzidas pelos primeiros grupos, alguns deles já engajados nos primeiros Programas de Pós-Graduação (PPGs) que começam a se constituir com esta temática. O volume crescente da produção da pesquisa em nichos restritos a físicos, químicos, biólogos, geólogos, matemáticos e profissionais das áreas afins, acabou por sugerir aos pesquisadores a fundação de entidades que os congregassem em um lócus de discussão de questões de pesquisa comuns. Surgem, assim, associações como a Sociedade Brasileira de Educação Matemática em 1988; a Sociedade Brasileira de Ensino de Biologia em 1997 e Associação Brasileira de Pesquisa em Educação em Ciências em 1997. Com a intensificação da produção científica relacionada ao Ensino de Ciências e Matemática, surge a preocupação com o mapeamento e organização dessa produção, e são criados bancos de dados sediados em várias universidades no país e programas de mestrado e doutorado com características afins. Neste contexto, em 2000 foi instalada na CAPES oficialmente a área de Ensino de Ciências e Matemática, composta inicialmente por cinco programas em funcionamento na USP, UFRGS, UFRN, UNICAMP e UNESP. 
Outro marco na área foi a sua reformulação ocorrida em 2011, por meio da Portaria CAPES n 83, de 6 de junho de 2011, quando passou a ser chamada "Ensino", uma denominação mais coerente com seus objetivos de abranger mais disciplinas.

Os programas da área focam suas pesquisas e produções no "ensino de determinado conteúdo". Eles têm como objeto a mediação do conhecimento em espaços formais e não formais de ensino e como principal objetivo a construção de conhecimento científico sobre este processo e sobre fatores de caráter micro e macroestrutural que nele interferem. A área de Ensino é, portanto, uma área essencialmente de pesquisa translacional, que busca construir pontes entre conhecimentos acadêmicos gerados em educação e ensino para sua aplicação em produtos e processos educativos na sociedade. A área contempla também expectativas relativas à nova missão e objetivos da CAPES para atuação na Educação Básica, conforme a estrutura estabelecida em 2007, e que resultou na criação de duas novas Diretorias: a Diretoria de Educação Básica (DEB) e a Diretoria de Educação à Distância (DED), além do respectivo Conselho Técnico-Científico da Educação Básica (CTC-EB), a Universidade Aberta do Brasil (UAB) e demais ações da CAPES e programas do MEC (CAPES, 2013a).

Em 2015 a Área de Ensino totalizava 128 Programas de Pós-Graduação, responsáveis por 31 cursos de Doutorado (5 isolados e 26 articulados com Mestrados Acadêmicos), 26 cursos de Mestrado Acadêmico e 71 cursos de Mestrado Profissional. Nestes PPGs, atuam cerca de 2.478 docentes responsáveis por titular 1.538 mestres e doutores na área no mesmo ano de 2015.

Atualmente esta é a área que concentra mais cursos na modalidade Mestrado Profissional, $56 \%$ do total de seus programas são profissionais.

Segundo Cevallos \& Passos (2012) esses cursos tornam-se alternativas interessantes, uma vez que as iniciativas de formação continuada comumente oferecidas aos professores dos ensinos fundamental e médio são cursos de curta duração, desarticulados de sua prática e não tem produzido resultados completos. Os cursos de MPs buscam atender às demandas da sociedade em meio às novas exigências requeridas do profissional professor que busca seu desenvolvimento na atual conjuntura das políticas voltadas para uma formação docente de qualidade (Cevallos \& Passos, 2012). De acordo com Ludke \& Cruz (2005), nossos cursos de formação de professores têm sofrido as consequências da separação entre teoria e prática, para os autores a solução para uma formação ideal inclui a pesquisa associada às práticas pedagógicas, e neste contexto o Mestrado Profissional se apresenta como uma grande oportunidade.

1.2 Contexto histórico e trajetória do Mestrado Profissional no Sistema Nacional de Pós-Graduação

Desde o surgimento da Pós-Graduação no Brasil, o Parecer CFE no 977/65 já propunha a criação de cursos de pós-graduação orientados à capacitação profissional. O documento já apontava a ilusão de se pretender formar no mesmo curso o profissional comum, o cientista e o técnico de alto padrão e a inviabilidade crescente da figura do técnico polivalente, assim, recomendava recorrer aos estudos pós-graduados, seja para complementar a formação do pesquisador, seja para o treinamento do especialista altamente qualificado. Ainda de acordo com o referido parecer, os três motivos fundamentais que exigiam, de imediato, a instauração do sistema de cursos pós-graduados são: formar professorado competente que possa atender à 
expansão quantitativa do nosso ensino superior garantindo, ao mesmo tempo, a elevação dos atuais níveis de qualidade; estimular o desenvolvimento da pesquisa científica por meio da preparação adequada de pesquisadores; assegurar o treinamento eficaz de técnicos e trabalhadores intelectuais do mais alto padrão para fazer face às necessidades do desenvolvimento nacional em todos os setores.

Apenas em 1995 com o documento intitulado "Programa de Flexibilização do Modelo de Pós-graduação Senso Estrito em Nível de Mestrado", a CAPES por meio da Portaria CAPES

no 47, de 17 de outubro de 1995 passou a estabelecer os requisitos e condicionantes para assegurar aos cursos de mestrado dirigidos à formação profissional, níveis de qualidade comparáveis aos vigentes no Sistema Nacional de Pós-Graduação. O reconhecimento da modalidade Mestrado Profissional se deu de fato em 1998 com a Portaria CAPES no 80/98 de 16 de dezembro de 1998, que revogou a Portaria anterior e trouxe orientações mais concretas sobre a relevância do Mestrado Profissional, simbolizando um avanço na discussão, embora ainda não tenha estipulado os critérios específicos de avaliação e acompanhamento da modalidade. Essa portaria já assumia que os cursos da modalidade tratada possuem vocação para o autofinanciamento.

Nos anos seguintes, de acordo com o registro de Barros et. al (2005), houve nas reuniões do Conselho Técnico Científico - CTC da CAPES várias discussões sobre o assunto que geraram alguns documentos como os documentos técnicos: "Pressupostos para avaliação de projetos de mestrado profissionalizante" de dezembro de 1999; "Capes - a necessidade de desenvolvimento da pós-graduação profissional e o ajustamento do Sistema de Avaliação às características desse segmento", de 12/11/2001; "Parâmetros para avaliação do mestrado profissional" de 15/03/2002; e os Seminários "Seminário sobre o Mestrado Profissional" em 05/09/2003; "Para Além da Academia - a pós-graduação contribuindo para a sociedade", em 01/04/2005, o qual contribuiu significativamente para o avanço na discussão e na implementação de mecanismos internos de avaliação e acompanhamento da modalidade na CAPES.

Ribeiro (2005) defendia o papel do MP no desenvolvimento econômico e social do Brasil com base em três constatações:

(...) primeira, a sociedade atual requer uma formação cada vez mais qualificada, mesmo para setores que não lidam com a docência nem com a pesquisa de ponta; segunda, com o aumento das titulações no País, constata-se que boa parte dos mestres e uma parte significativa dos doutores encaminham-se para um destino que não é o ensino superior; e, terceira, a inexistência de preconceito da Capes quanto à transferência de conhecimento científico para as empresas ou para o mercado, desde que a sociedade como um todo, e o setor público e os movimentos sociais em particular, também sejam alvo dessa transferência (Ribeiro, 2005, p.1011).

Mais recentemente a Portaria Normativa no 17, de 28 de dezembro de 2009 passou a regular o mestrado profissional. Com essa Portaria, a implementação de novos cursos de MP, bem como seu acompanhamento, passou a ter normas bem definidas, permitindo definitiva organização da modalidade. A legislação ainda não prevê a concessão de bolsas de estudo, mas passa a admitir exceções em áreas priorizadas. Este é o caso concreto dos PROFS - Programas 
formados por redes institucionais com bolsas da CAPES para professores em exercício na rede pública.

Atualmente a Diretoria de Avaliação da CAPES vem tratando de forma diferenciada a avaliação e a recomendação dos cursos de MP, sendo que cada documento de área desde 2009 estabelece distintos e próprios parâmetros de avaliação de cursos novos de Mestrado Acadêmico, Profissional e Doutorado, os quais serviram também para nortear a Avaliação Trienal de 2010, quando pela primeira vez as áreas tiveram condições de avaliar com melhores condições de dados e com maior acurácia as diferentes modalidades de mestrado stricto sensu.

\subsection{Características e definições da modalidade Mestrado Profissional}

Constitui um tipo de grau acadêmico em nível de pós-graduação senso estrito, voltado ao aprofundamento da formação científica e profissional e à ampliação da experiência prática dos egressos de cursos de graduação, capacitando-os a aplicar conhecimentos, tecnologias e resultados científicos à solução de problemas em seu ambiente de atuação profissional.

De acordo com o documento "Parâmetros para avaliação do mestrado profissional" são características de sua natureza:

a) associação da estrutura curricular, e das experiências profissionais oferecidas pelo curso às demandas da sociedade ou às tendências identificadas ou novas tendências a serem prospectadas;

b) construção em torno de problemas de interesses comuns entre as instituições que oferecem o curso e as empresas ou instituições governamentais ou não governamentais envolvidas;

c) implantação e desenvolvimento respaldado por esquemas de intercâmbio com empresas e instituições governamentais e não governamentais para melhor qualificar seus profissionais. É necessário que o MP possua um plano estruturado articulando a instituição que oferta o curso e as instituições sociais nela interessada, comprovando os vínculos e relações de intercâmbio (Oller et. al. 2005, p. 151).

As universidades, centros universitários, instituições de ensino superior reconhecidas pelo MEC, instituições de pesquisa e instituições de desenvolvimento tecnológico, desde que possuam os pré-requisitos específicos exigidos por cada área, estão qualificados para oferecer programas de MP.

Os Mestrados Profissionais são intrinsecamente diferentes dos Acadêmicos sob vários aspectos. Segundo Ribeiro (2005):

A principal diferença entre o mestrado acadêmico (MA) e o mestrado profissional (MP) é o produto, isto é, o resultado almejado. No MA, pretende-se pela imersão na pesquisa formar, a longo prazo, um pesquisador. No MP, também deve ocorrer a imersão na pesquisa, mas o objetivo é formar alguém que, no mundo profissional externo à academia, saiba localizar, reconhecer, identificar e, sobretudo, utilizar a pesquisa de modo a agregar valor a suas atividades, sejam essas de interesse mais pessoal ou mais social. Com tais características, o MP aponta para uma 
clara diferença no perfil do candidato a esse mestrado e do candidato ao mestrado acadêmico (Ribeiro, 2005, p. 15).

Concluindo, os mestrados profissionais têm o compromisso de promover o encurtamento das distâncias que historicamente se criaram entre a academia e outros setores da sociedade, cujas necessidades já existentes ou emergentes cada vez mais enfrentam os desafios de uma atuação mais efetiva de transformação. Esta situação de desafios é influenciada pelo avanço da ciência e pela competição entre mercados e premida pela necessidade de um desenvolvimento regional que se projete para além de suas fronteiras (Feltes \& Baltar, 2005).

\subsection{A modalidade Profissional no Sistema Nacional de Pós-Graduação}

O Mestrado Profissional, objeto deste estudo, constitui modalidade de formação pósgraduada stricto sensu visando à capacitação de recursos humanos qualificados para o exercício da prática profissional avançada e transformadora de ações e processos aplicados, com ênfase na produção técnico-científica, na pesquisa aplicada e na proposição de inovações e aperfeiçoamentos para a solução de problemas específicos, que permitam o avanço da área em âmbito nacional, regional ou local.

Segundo Fischer (2003), as vertentes acadêmica e profissional podem ser assim conceituadas: a acadêmica, cujo propósito é formar pesquisadores consubstancia-se na oferta de doutorado, já a profissional tem como objetivo a formação de profissionais capacitados para o desempenho de funções outras que não a pesquisa acadêmica, mediante a oferta de cursos voltados para aplicação em um campo profissional definido de conhecimentos e métodos científicos atualizados, neste caso o mestrado tem o caráter de curso terminal, enquanto no primeiro cabe ao mestrado o papel de curso propedêutico.

De acordo com Nepomuceno \& Gomes (2012) os coordenadores de PPGs utilizam na definição de suas estratégias de ação duas observações distintas: a comparação dos programas ou políticas educacionais com os critérios e as avaliações elaboradas pelas áreas específicas do Sistema de Avaliação de cursos da CAPES e, além disso, fazem a captação das percepções do público interno (alunos, professores e colaboradores) e do público externo (aqueles que demandam ou se beneficiam do trabalho desenvolvido pela instituição). Nesse contexto, é válida a recente problemática da avaliação dos cursos na modalidade profissional, já que esta apresenta uma situação peculiar ao conceder aos seus egressos os mesmos direitos e prerrogativas garantidos aos oriundos do mestrado acadêmico, apesar das diferenças marcantes tanto na conformação do curso, como no objetivo de formação do seu egresso. Diversos estudos consideram a visão tanto desse público interno como a do público externo, principalmente quanto ao desempenho profissional de seus egressos e se utilizam de técnicas de questionários, formulários, entrevistas, análise estatística multivariada, análise envoltória de dados e análise multicritério a exemplo de Moreira, Hortale \& Hartz (2004), Ribeiro \& Costa (2005), Rocha (2006), Freitas, Rodrigues \& Costa (2009).

A proposta deste estudo é agora investigar do ponto de vista do órgão regulador quais os impactos originados pelos cursos de pós-graduação de Mestrado Profissional não apenas no mercado profissional, mas no Sistema Nacional de Pós-Graduação - SNPG. Assim, neste estudo procuramos responder as seguintes questões: Qual o percentual de submissão e os índices de recomendação por modalidade das propostas de cursos novos de Pós-Graduação submetidas em 
Ensino? Quais são os fatores limitantes para aprovação desses novos programas de Mestrados Profissionais? Quais tem sido os resultados obtidos pelos Programas de Pós-Graduação nível Mestrado Profissional, em comparação com o nível Mestrado Acadêmico na área de Ensino nas três últimas avaliações trienais (2013, 2010 e 2007)? Como está a distribuição geográfica, por nota e por dependência administrativa dos programas de pós-graduação de nível Mestrado Profissional ofertados pela área de Ensino? Como está sua produtividade científica em comparação com os programas acadêmicos da área de Ensino?

\section{METODOLOGIA}

De acordo com Vergara (2005) a pesquisa pode ser classificada com base nos procedimentos técnicos utilizados. Considerando essa classificação, o presente estudo é caracterizado como pesquisa bibliográfica, a qual se deu pela análise das informações obtidas por revisão de literatura. A pesquisa bibliográfica consiste em um estudo sistematizado desenvolvido em material publicado em livros, revistas, jornais e redes eletrônicas, isto é, material acessível ao público em geral (Vergara, 2005). Este estudo adotou também a pesquisa documental, pelo fato de ter levantado informações e dados que fazem parte do Sistema Nacional de Pós-Graduação e documentos disponibilizados pela Diretoria de Avaliação da CAPES. Pesquisa documental é aquela realizada em documentos conservados no interior de órgãos públicos e privados de qualquer natureza, ou com pessoas: registros, anais, regulamentos, circulares, ofícios, memorandos, balancetes, comunicações informais, filmes, microfilmes, fotografias, vídeo-tape, informações em disquete, diários, cartas pessoais, entre outros (Vergara, 2005).

Quanto à forma de abordagem dos dados, esta é uma pesquisa quantitativa, ou seja, utilizando métodos estatísticos, tabelas e gráficos, traduziu em números, opiniões e informações para classificá-los e organizá-los. Segundo Richardson (1989) o método quantitativo, como o próprio nome indica, caracteriza-se pelo emprego da quantificação tanto nas modalidades de coleta de informações, quanto no tratamento delas por meio de técnicas estatísticas, desde as mais simples até as mais complexas. As análises foram feitas a partir da leitura e consolidação dos dados disponíveis nos bancos de dados e sistemas eletrônicos utilizados pela Diretoria de Avaliação - DAV, tais como o Coleta CAPES, o Sistema Nacional de Pós-Graduação, a Plataforma Sucupira, o Sistema GeoCapes e a literatura especializada sobre Ensino Superior de PósGraduação e Políticas Públicas para a Educação.

$\mathrm{Na}$ área de Ensino, a modalidade profissional foi comparada com a acadêmica quanto ao número de propostas de cursos novos avaliadas no período entre 2000 a 2015, o número de programas em funcionamento em 2015, o percentual de propostas recomendadas e não recomendadas. As propostas não recomendadas foram analisadas para estimar quais os principais fatores limitantes para sua entrada no Sistema Nacional de Pós-Graduação.

Os programas existentes foram analisados quanto ao seu crescimento no SNPG e desempenho nas últimas três avaliações periódicas (2013, 2010 e 2007). Também foi analisada a sua distribuição geográfica, por dependência administrativa, pelo perfil de produtividade de seus alunos egressos.

Os programas de Mestrado Profissional foram comparados com os de Mestrado Acadêmico quanto à sua produtividade científica informada nos triênios de 2004 - 2006; 2007 - 
2009; e 2010 - 2012. A variável utilizada para medir a citada produtividade dos programas foi a produção científica dos mesmos, representada pelo número de artigos científicos, livros, capítulos de livros e patentes declarados no Coleta de dados.

\section{RESULTADOS E DISCUSSÃO}

\subsection{Propostas de Cursos Novos na área de Ensino}

Nestes 15 anos de observação desde a constituição da área em 2000 a CAPES recebeu 10.158 propostas de cursos novos para análise de mérito. Deste total, 272 foram submetidas à área de Ensino, sendo 141 profissionais (52\%) e 131 acadêmicas (48\%) (Figura 1a). Estes números conferem com a mesma proporção de programas em funcionamento em 2015 (Figura 1b), já que dos 128 PPGs ativos neste ano, 71 são Mestrados Profissionais (55\%) enquanto 57 são acadêmicos (45\%) distribuídos em 26 programas com Mestrado e Doutorado, 26 só com Mestrado e 5 oferecem só o Doutorado.

Uma vez que a proposta de curso novo passa por todo o processo de análise e é, por fim, recomendada, ela ainda tem um ano para entrar em funcionamento. Considerando esse intervalo de tempo, uma proposta submetida em determinado ano poderá se tornar um novo programa em funcionamento, ou no caso do doutorado se somar a um programa já existente, nos anos subsequentes.

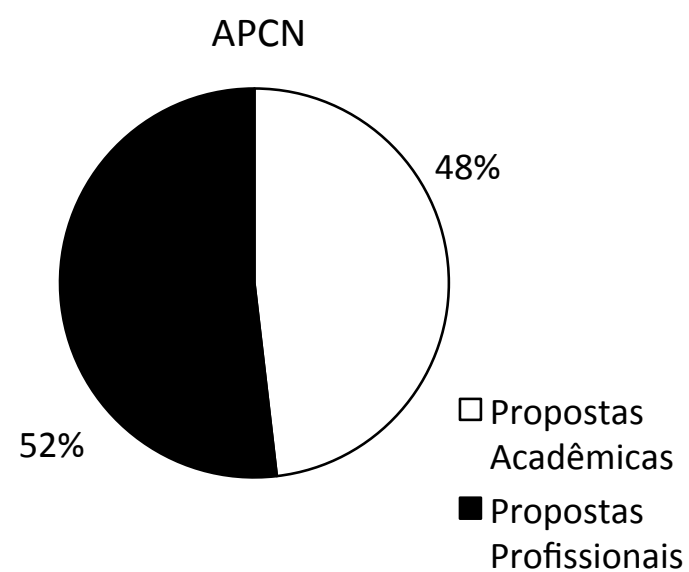

a) Propostas de cursos novos

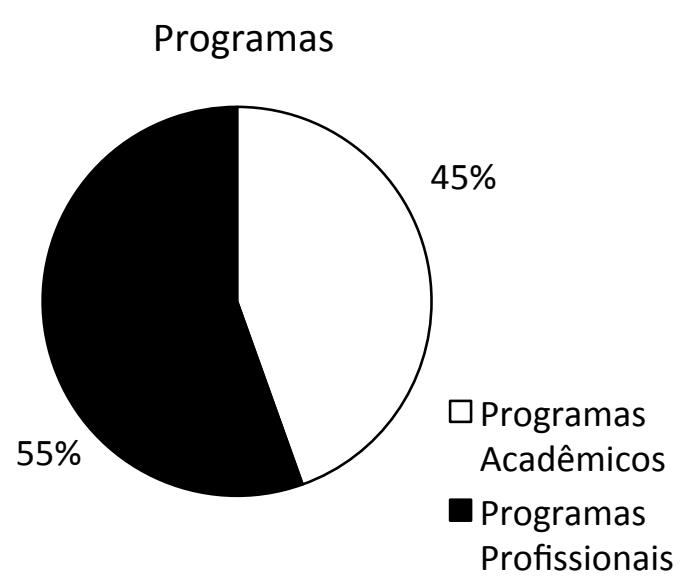

b) Programas em funcionamento

Figura 1. Comparação entre os programas profissionais e os acadêmicos da área de Ensino quanto à: (a) Distribuição das propostas de cursos novos e (b) Distribuição de Programas de Pós-Graduação em funcionamento no período 2000 a 2015. Fonte: SNPG/DAV/CAPES.

Conforme pode ser observado na Figura 2, a partir de 2010 houve um aumento da submissão de propostas de cursos novos. Aumento este que se nota principalmente na modalidade profissional, já que neste ano de 2010, por exemplo, a comissão de Ensino avaliou 17 propostas de cursos novos de Mestrado Profissional, mas somente 6 de Mestrado Acadêmico e/ou Doutorado. Embora ocorra um decréscimo no número de propostas apresentadas em 2013 e 2015, em geral há um aumento que demonstra a importância da regulamentação dos MPs pela 
Portaria CAPES/MEC no 17/2009, já que nos dois anos anteriores apenas quatro propostas de MP foram submetidas para apreciação.

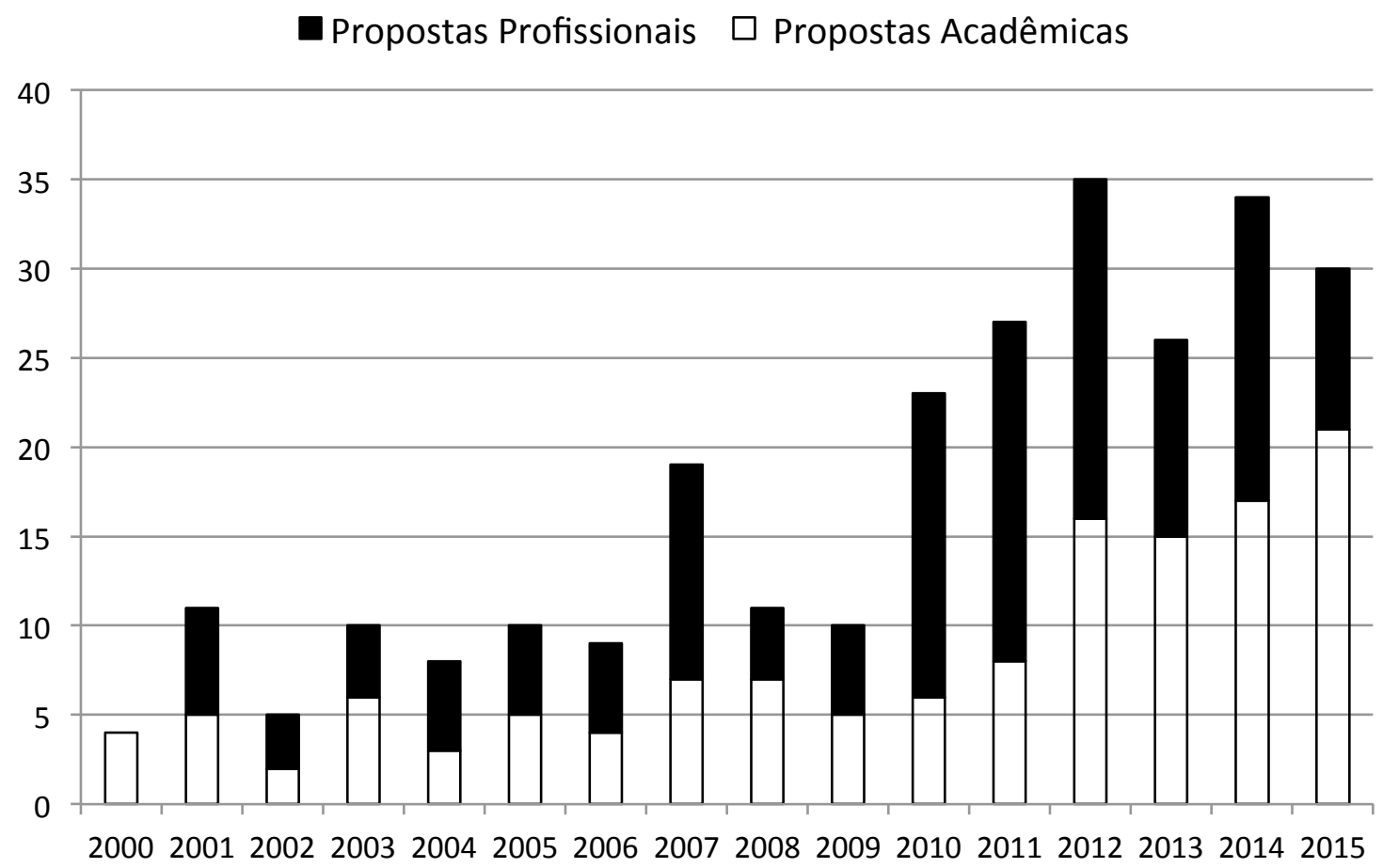

Figura 2. Propostas de cursos novos de Pós-Graduação stricto sensu submetidas à avaliação da área de Ensino na CAPES, distribuídas por modalidade (Acadêmica e Profissional) no período 2000 a 2015. Fonte: SNPG/DAV/CAPES.

No entanto, cabe destacar que este predomínio da submissão de propostas profissionais não reflete a qualidade das mesmas, já que das 17 propostas de MP avaliadas em 2010, apenas 6 foram aprovadas. No geral, desde sua criação em 2000 a área recebeu 141 propostas de cursos novos MP e 131 de MA/D. Quando comparamos os índices de recomendação das propostas por modalidade, notamos que as acadêmicas têm índice de recomendação maior que as profissionais, como podemos ver na Figura 3.

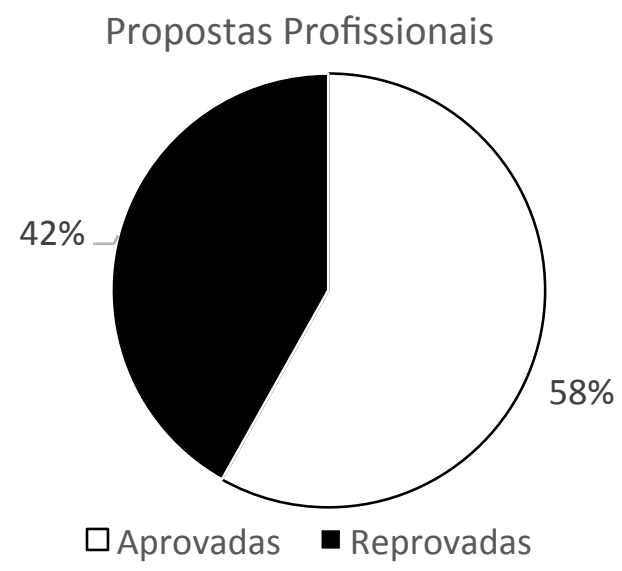

a)

\section{Propostas Acadêmicas}

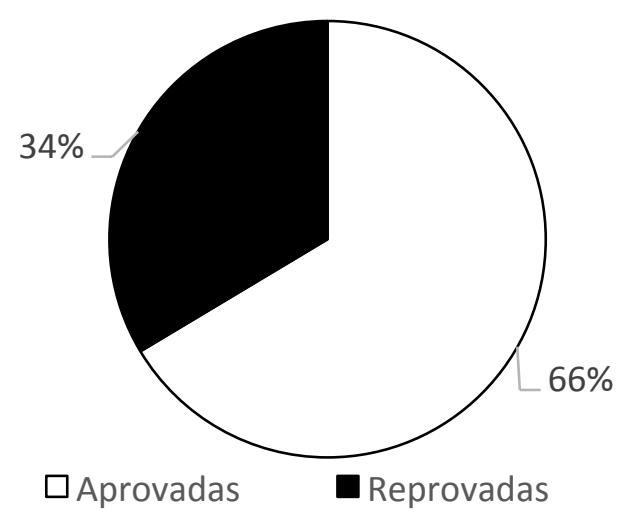

b) 
Figura 3. Percentual de aprovação das propostas de cursos novos submetidas à área de Ensino na CAPES, distribuídas por modalidade A) profissional e B) acadêmica, no período 2000 a 2015 . Fonte: SNPG/DAV/CAPES.

Alves e Del Pino (2015) calcularam em 51\% o índice de recomendação de todas as propostas de cursos novos submetidas à avaliação da CAPES no período de 2000 a 2013. Quando comparado a esse índice, notamos que em relação às 48 áreas de conhecimento de forma geral, a área de Ensino tem uma proporção maior de propostas acadêmicas recomendadas, $66 \%$ do total, bem como as profissionais com $58 \%$ do total de propostas recomendadas. Esse resultado é reflexo do amadurecimento das propostas submetidas em Ensino, pois muitos programas têm obtido a recomendação necessária para seu reconhecimento no SNPG. No entanto, ao olharmos as propostas profissionais verificamos que embora esta seja a modalidade predominante na área, uma grande parte das propostas de cursos novos não é recomendada, o que leva à reflexão sobre quais as razões para a reprovação de quase metade das propostas analisadas.

A análise das propostas é feita por uma comissão constituída especificamente para esse fim e formada por pares, ou seja, por membros da comunidade acadêmica atuantes em Programas da Área. Essa comissão segue os critérios de avaliação previamente estabelecidos no Documento da Área vigente e, em seguida, essa primeira análise da comissão de área é submetida à apreciação do Conselho Técnico Científico da Educação Superior/ CTC-ES. O resultado da avaliação é uma ficha composta por cinco quesitos, os quais são: 1) Comprometimento da Instituição; 2) Infraestrutura; 3) Proposta do curso; 4) Dimensão e regime de trabalho do corpo docente; 5) Produtividade docente e consolidação da capacidade de pesquisa. A nota atribuída às propostas varia de 1 a 2 para recusa da proposta, e de 3 a 7 para sua recomendação de funcionamento.

Das 141 propostas de cursos profissionais submetidas à avaliação entre 2000 e 2015, 59 foram reprovadas. Esse número corresponde a $42 \%$ do total. Ao analisar suas fichas de avaliação, verificamos que os fatores limitantes para aprovação são principalmente os quesitos 3 , referente à adequada concepção da proposta do curso, e o quesito 5 , que trata da produtividade docente e consolidação da capacidade de pesquisa. Estes quesitos foram avaliados de forma positiva em apenas $15 \%$ das propostas não recomendadas. O quesito 4 que trata da dimensão e regime de trabalho do corpo docente também foi avaliado negativamente na maioria das propostas (74\%) conforme mostra a Figura 4. 


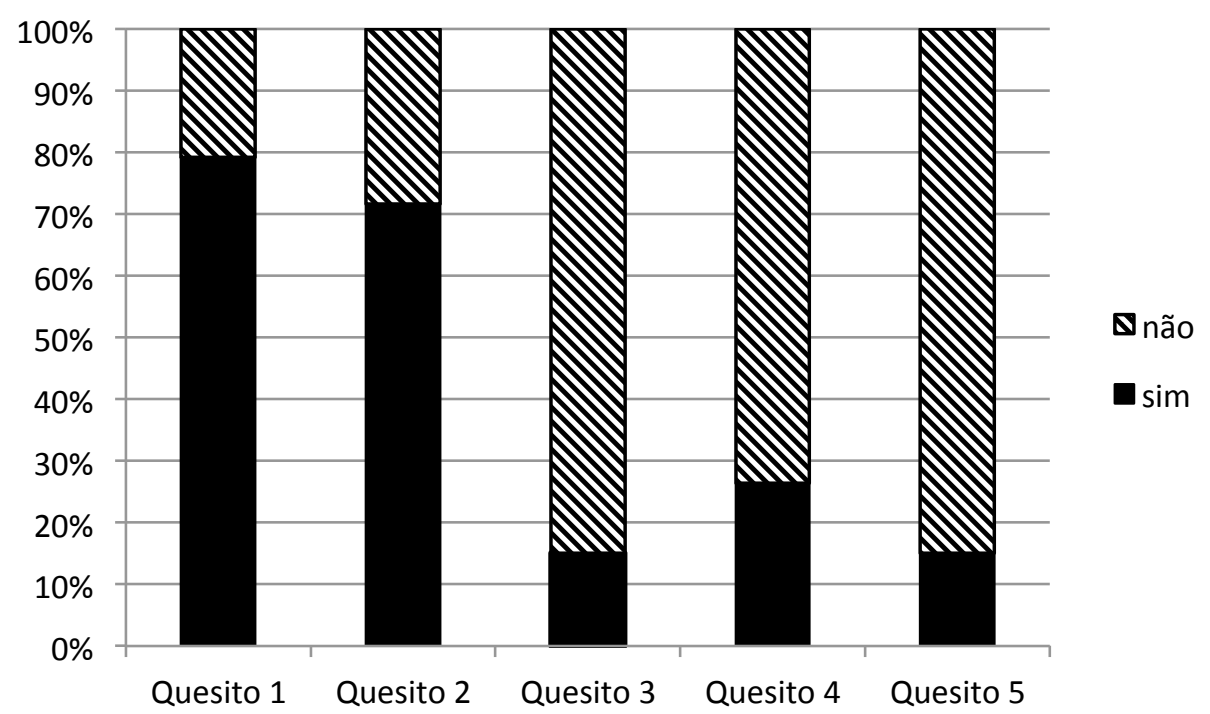

Figura 4 - Avaliação dos quesitos da ficha de recomendação das propostas de cursos novos de Mestrado Profissional submetidas à avalição da área de Ensino no período de 2000 a 2015. Fonte: SNPG/DAV/CAPES.

Mesmo atendendo aos requisitos de comprometimento institucional, e infraestrutura adequada, é necessário envidar esforços para fortalecer a produtividade docente, sua dimensão e regime de trabalho e consolidação da capacidade de pesquisa, bem como articular adequadamente a proposta.

A Área orienta que a proposta do curso de Mestrado Profissional em Ensino deve mostrar clareza e coerência em seus objetivos, título, área(s) de concentração, linha(s) de pesquisa, projetos de pesquisa e disciplinas do curso, hierarquizados em ordem decrescente de abrangência; deve integrá-los, articulá-los e sua matriz curricular deve contemplar disciplinas obrigatórias e eletivas que ofereçam conteúdos de ensino/didáticos relacionados com conteúdos das respectivas áreas específicas, que considerem teorias e resultados da pesquisa relacionada ao ensino e à aprendizagem. Quanto à produção intelectual, a formação de origem dos docentes e as suas trajetórias de estudo e pesquisa devem contemplar as ênfases do curso proposto. Essa trajetória deve se concretizar na forma de produção intelectual comprovada, e na capacidade de formação de recursos humanos. O volume da produção do corpo docente deve refletir investimento na Área de Ensino, considerando artigos, livros, capítulos de livros, textos completos em anais de eventos e produção técnica qualificada destinada ao ensino em todas as suas modalidades. É importante que as publicações qualificadas sejam bem distribuídas entre os membros do corpo docente.

\subsection{Acompanhamento e Avaliação Trienal}

A partir da recomendação pela CAPES, o curso de Pós-Graduação stricto sensu passa a ser reconhecido pelo Conselho Nacional de Educação (CNE) e integrar o SNPG, sendo periodicamente reavaliado nas "Avaliações Trienais" cuja última reunião ocorreu em 2013 e abrangeu os dados coletados entre janeiro de 2010 e dezembro de 2012. No entanto, desde a Resolução do Conselho Superior da CAPES no 05, de 11 de dezembro de 2014, a reavaliação dos cursos de Pós- 
Graduação stricto sensu do SNPG passou a ser quadrienal, sendo que a próxima avaliação ocorrerá em 2017.

O crescimento do SNPG vem sendo acompanhado pela área de Ensino. Desde sua criação em 2000 houve o aumento dos cinco programas iniciais para 128 programas até 2015 , conforme mostra a Figura 5. Essa expansão é indicativa da consolidação da identidade da área e da demanda por Pós-Graduação no país.

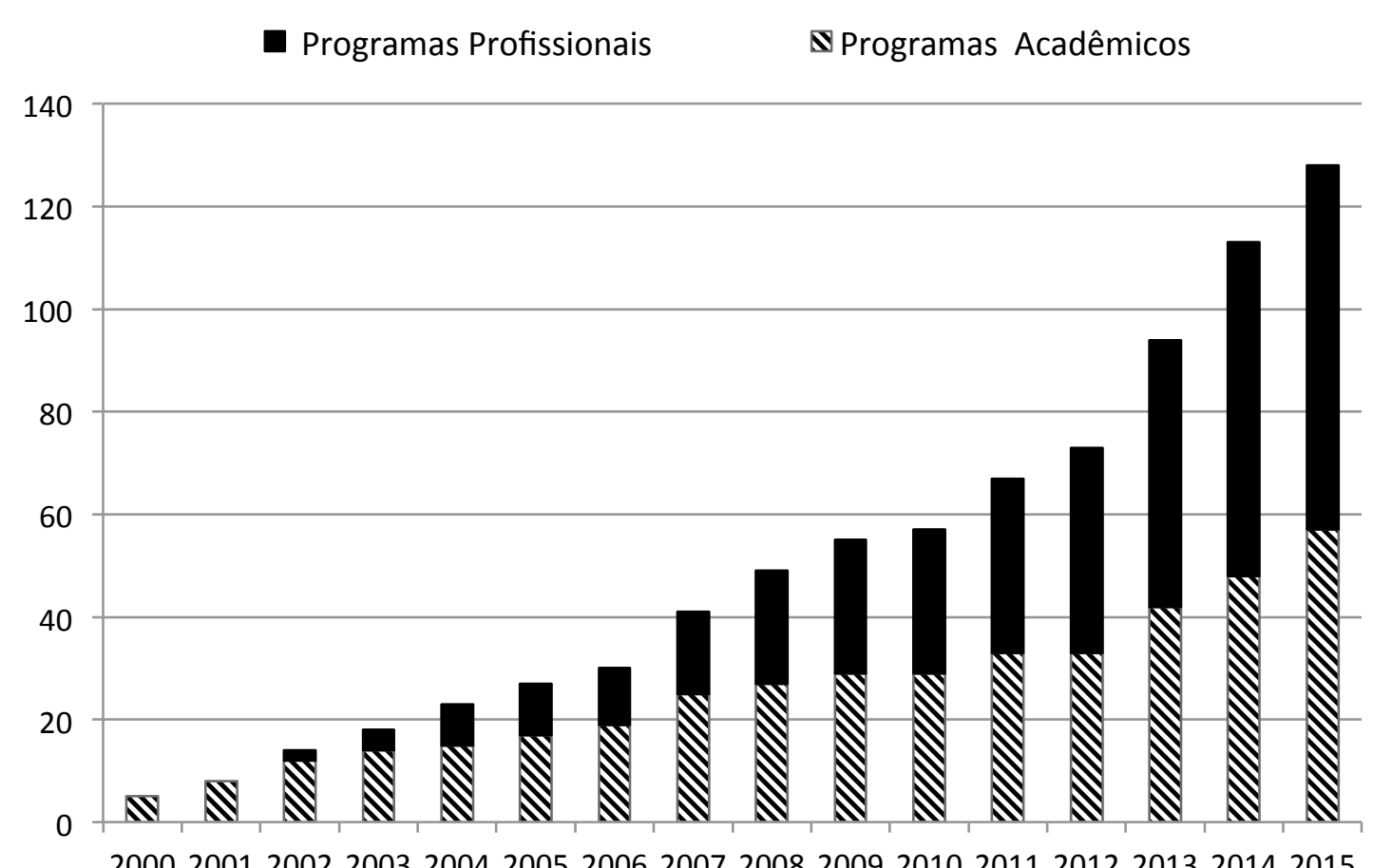

Figura 5. Expansão do número de Programas de Pós-Graduação da área de Ensino no período de 2000 a 2015. Fonte: SNPG/DAV/CAPES.

Dos 128 Programas de Pós-Graduação stricto sensu de Ensino em funcionamento até 2015, 75 já foram reavaliados nas Avaliações Trienais. Os demais ainda não foram reavaliados porque iniciaram suas atividades letivas a partir do ano de 2013 e entrarão na clientela da próxima avaliação que acontecerá em 2017.

Analisando o desempenho dos programas reavaliados pela CAPES, dentre os Mestrados Profissionais em Ensino, 17 programas aumentaram o desempenho subindo de nota 3 para 4, ou 4 para 5 nas últimas Avaliações; 21 permaneceram com a mesma nota e 2 foram rebaixados, sendo que um desses foi descredenciado. Dentre os programas Acadêmicos a situação foi semelhante: 17 programas subiram de nota e 18 permaneceram na mesma, porém nesta modalidade nenhum curso teve nota reduzida ou foi descredenciado.

Os MPs têm predominantemente nota 3, mas como podemos observar na Figura 6, apesar de haver poucos programas com nota 5 , a cada reavaliação vem aumentando o número de programas profissionais com nota 4 . Os programas com nota 4 correspondiam a apenas $9 \%$ do total na Avaliação Trienal de 2007, 22\% na Avaliação de 2010 e na Avaliação de 2013 já somavam $41 \%$ do total de programas. Este dado revela que, após recomendação pela CAPES, os Programas de Pós-Graduação stricto sensu ofertados em Ensino tem não só aumentado em quantidade, mas 
também em qualidade, pois a nota obtida é, entre outros fatores, reflexo do investimento em produção científica e aperfeiçoamento do corpo docente.

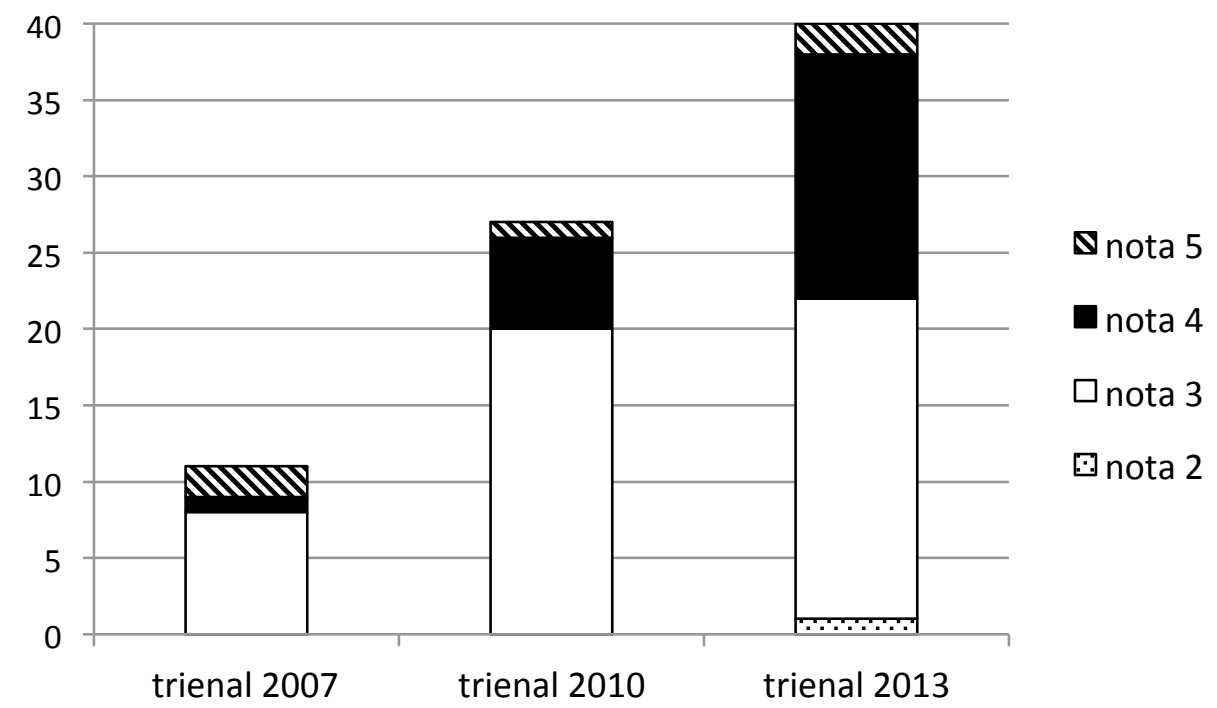

Figura 6. Distribuição dos Programas de Pós-Graduação em nível Mestrado Profissional da área de Ensino por nota obtida nas últimas Avaliações Trienais. Fonte: SNPG/DAV/CAPES.

Como mostra a Figura 7, atualmente prevalecem em funcionamento os programas com nota 3 em ambas as modalidades e é notória a carência de programas com nota igual ou acima de 5 , especialmente nos MPs, sendo que atualmente a área ainda não possui programa com nota 7. Isso se deve ao fato de a maioria dos programas serem recém-criados e usualmente recebem nota 3 na recomendação. Na medida em que forem sendo reavaliados e evoluindo em produtividade científica, suas notas tendem a aumentar. De acordo com as normas vigentes, programas de MP não recebem nota 6 e 7, pois não tem Doutorado e nem inserção internacional.

Programas Profissionais

$\square$ Nota $3 \quad$ Nota $4 \quad \mathbf{N}$ Nota 5

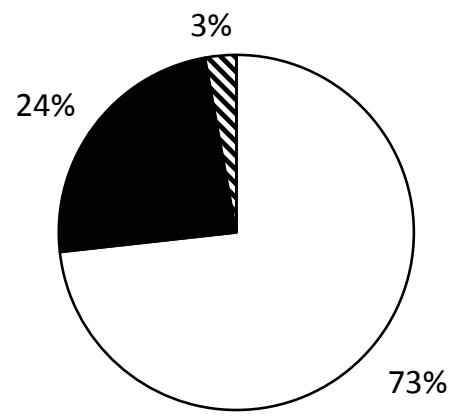

a)
Programas Acadêmicos

$\square$ Nota $3 \square$ Nota $4 \square$ Nota $5 \square$ Nota 6

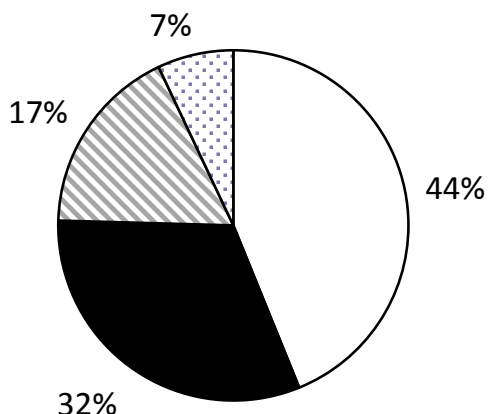

b)

Figura 7. Distribuição dos Programas de Pós-Graduação da área de Ensino por nota no ano de 2015. a) Programas de Mestrado Profissional. b) Programas de Mestrado Acadêmico e/ou Doutorado. Fonte: SNPG/DAV/CAPES. 


\subsection{Perfil e Produtividade dos programas}

Quanto à dependência administrativa das instituições que oferecem programas em Ensino, prevalecem as universidades públicas, principalmente as federais, conforme apresenta a Figura 8 a seguir. As instituições particulares se destacam quanto à oferta de MPs: são 14 particulares ofertando cursos em todas as cinco regiões do país.

O setor privado é importante titulador de mestres profissionais, dados de 2015 mostram que nesse ano as instituições particulares cobriam 34\% dos programas profissionais de todas as áreas do SNPG, enquanto apenas $15,5 \%$ dos programas acadêmicos eram oferecidos por particulares no mesmo período. Igualmente, na área de Ensino 15\% dos programas acadêmicos são oferecidos pela iniciativa privada, entretanto a proporção de programas profissionais oferecidos é menor, cerca $20 \%$ dos programas são oferecidos por particulares.

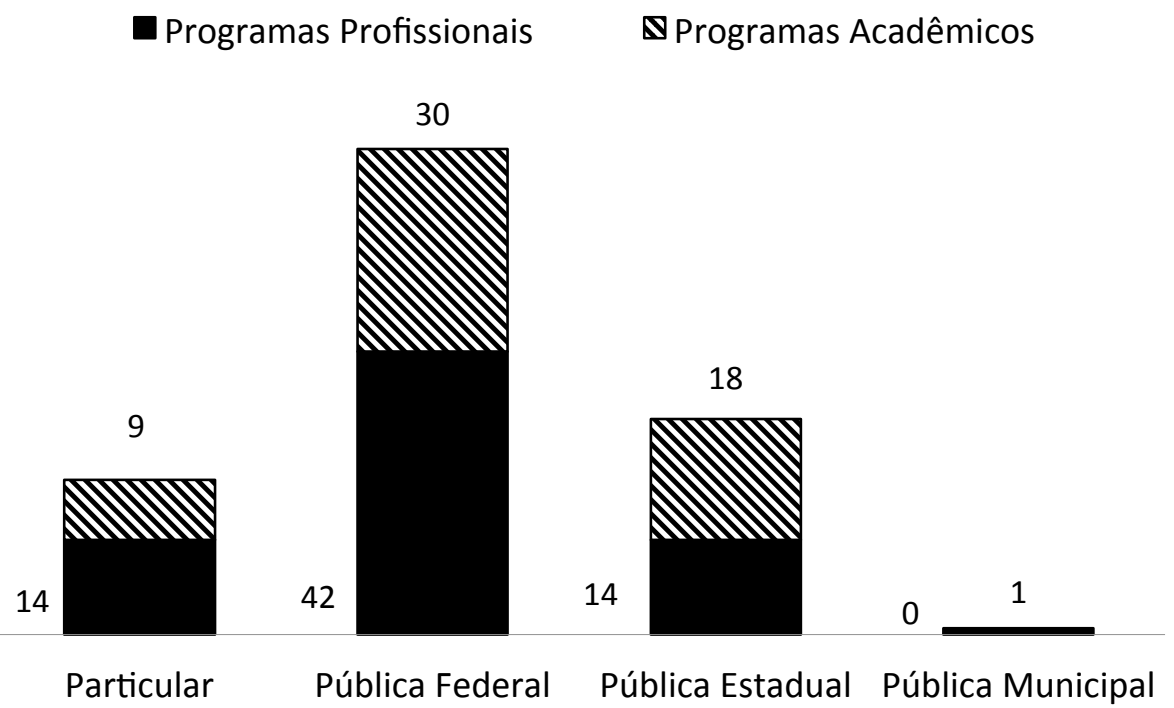

Figura 8. Comparação da distribuição dos Programas de Pós-Graduação Profissionais e Acadêmicos da área de Ensino por dependência administrativa da instituição de ensino no ano de 2015. Fonte: SNPG/DAV/CAPES.

Os programas estão distribuídos nas cinco regiões do país e seguem o mesmo padrão de todo o SNPG: a maioria dos cursos se concentra na região sudeste, seguida da região sul, enquanto o Norte, Nordeste e Centro-Oeste do país ainda tem um pequeno número de Programas, como podemos ver na Figura 9. 


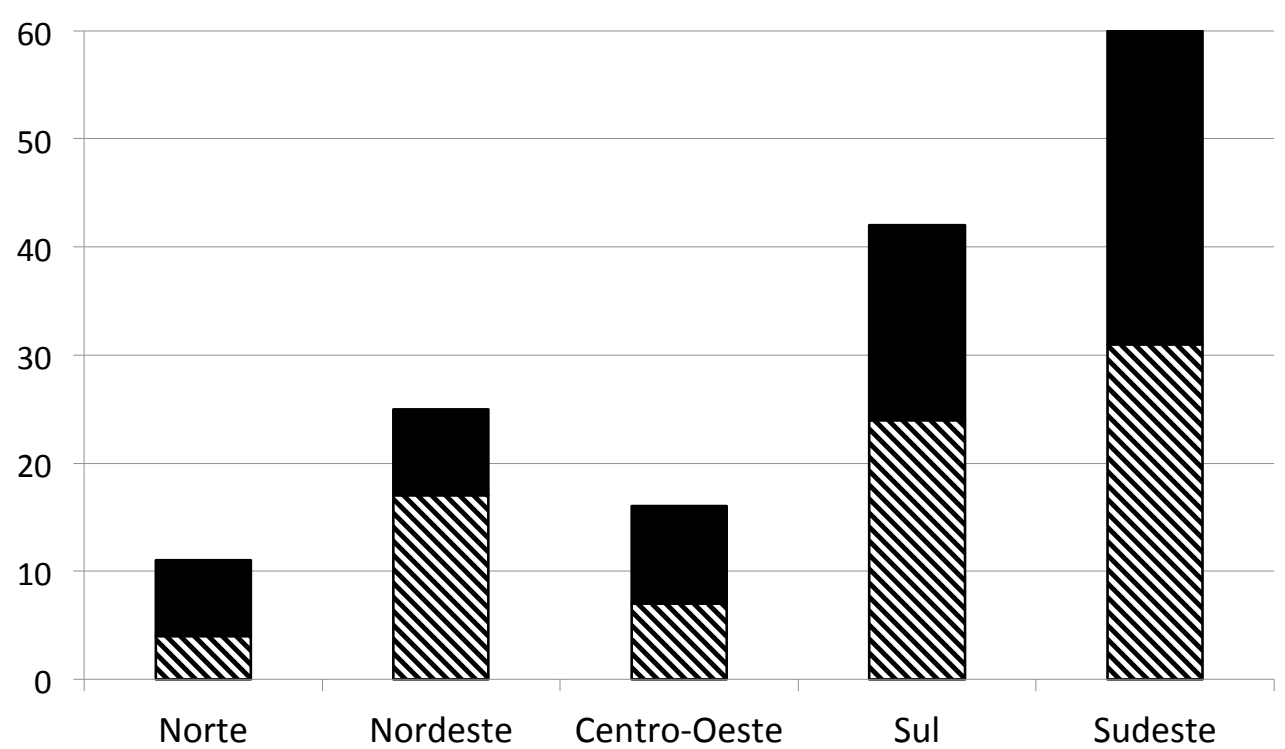

Figura 9. Distribuição por região geográfica dos Programas de Pós-Graduação em nível profissional e acadêmico da área de Ensino em atividade no ano de 2015. Fonte: SNPG/DAV/CAPES.

Desde sua criação em 2000, um total de 9.688 alunos já foram titulados na área, sendo 3.701 de MP, 4.922 de MA e 1.065 de Doutorado. Em 2011 a área titulou o mesmo número de alunos em cursos de MP e em cursos de MA, mas desde 2012 tem titulado majoritariamente alunos de MP (Figura 10). Esse resultado reflete a importância da regulamentação pela Portaria CAPES/MEC no 17 no ano de 2009, pois demonstra que a partir desse marco regulatório mais alunos se matricularam, culminando na sua titulação dentro do tempo regulamentar de 24 meses. Isso mostra, ainda, que a despeito da proibição de concessão de bolsas para essa modalidade, a procura pelo MP na área é cada vez maior, ao ponto de em 2015 dos 6.076 alunos matriculados, 1.582 eram de Doutorado, 1.934 de MA enquanto 2.560 eram alunos de MP executando as mesmas atividades acadêmicas, porém sem nenhum tipo de fomento. 


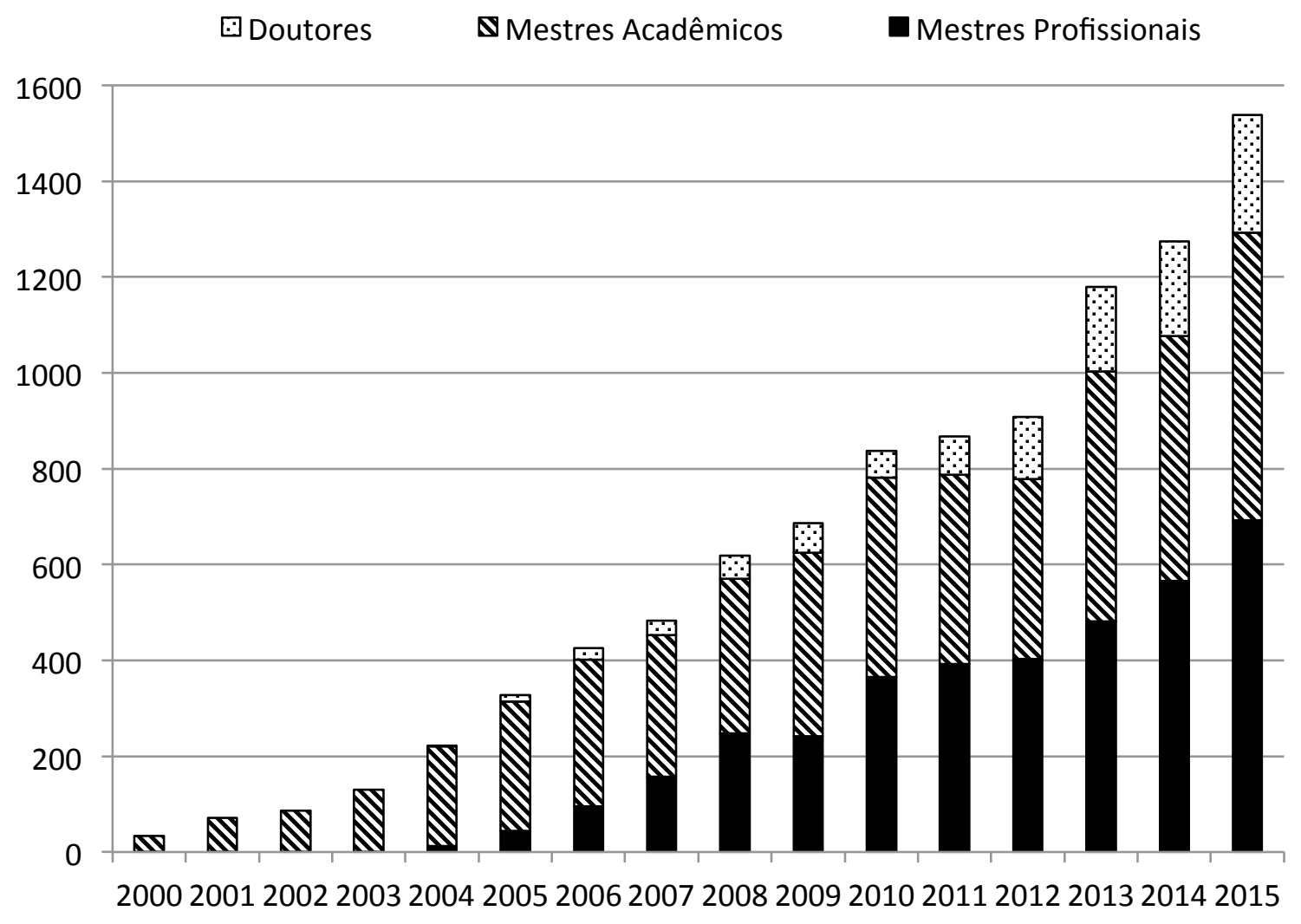

Figura 10. Crescimento do número de alunos titulados na área de Ensino distribuídos por modalidade (Mestrado Profissional, Mestrado Acadêmico e Doutorado), no período de 2000 a 2015. Fonte: SNPG/DAV/CAPES.

A produtividade científica da área é expressa nas publicações acadêmicas em artigos em periódicos, livros e capítulos de livros e comunicações em eventos; além da produção técnica voltada para a educação em sentido amplo.

Ao analisar a produtividade científica dos programas da área a fim de comparar as modalidades ao longo das três avaliações trienais, verificamos que no geral os programas acadêmicos se sobressaem em relação aos profissionais (Figura 11). Esse resultado é esperado pois até 2012 o número de alunos em PPGs Acadêmicos era maior do que em PPGs profissionais, e continua maior até hoje se somarmos o volume de Mestrados Acadêmicos e Doutorados. Além disso, a ausência de fomento pode ter um impacto negativo na capacidade produtiva dos MPs. É preciso continuar a monitorar sua produtividade e relacioná-la com o crescimento da modalidade, além disso, a própria área reconhece em seu documento de área e no seu relatório da Avaliação Trienal a necessidade de criar critérios específicos para avaliar a produtividade científica dos MPs (CAPES, 2013a; b). 


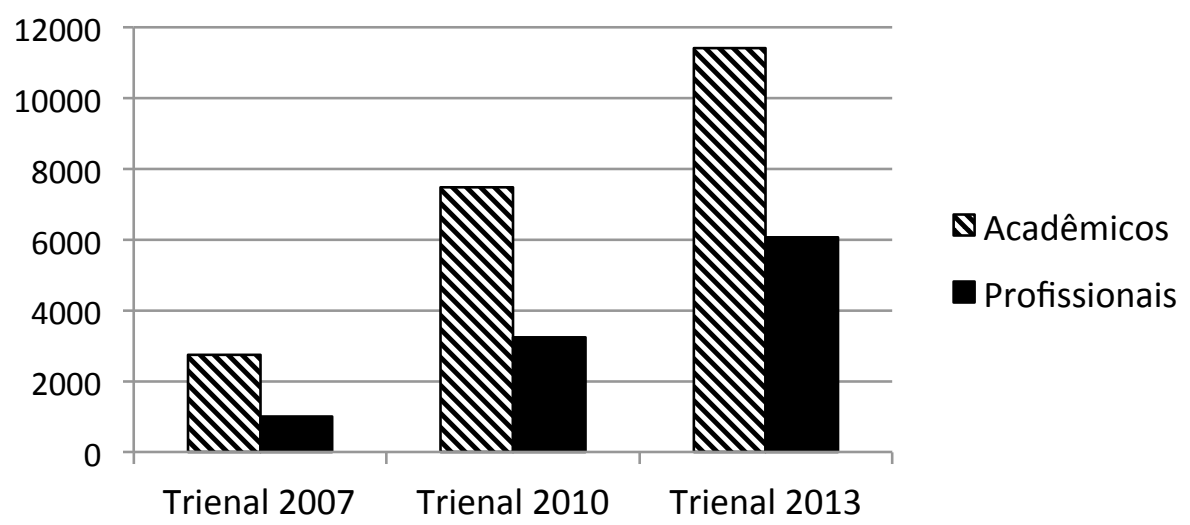

Figura 11. Número de produtos informados pelos programas da área de Ensino distribuídos por modalidade do programa (Mestrado Profissional ou Mestrado Acadêmico e Doutorado), nas Avaliações Trienais de 2007, 2010 e 2013. Fonte: SNPG/DAV/CAPES.

Quanto à produtividade técnica dos egressos, foram somados todos os produtos técnicos informados pelos egressos dos PPGs, distinguindo os Acadêmicos dos Profissionais. Os programas informam no Coleta de Dados: Artigos em Periódicos, Livros, Capítulos de Livro, Coletâneas, Verbetes e demais tipos de produção bibliográfica, Serviços Técnicos, Cursos de Curta Duração, Editorias, Apresentação de trabalhos em eventos, Desenvolvimento de Produtos, Aplicativos, Material Didático e Técnicas, Programas de Rádio e TV, Produção Artística, etc.

As observações sobre os egressos iniciam em 2004, já que o primeiro MP em Ensino se instalou em 2002. Podemos observar na Figura 12 que a produtividade dos alunos egressos de programas de MP, ainda que apresente um impulso em 2009 com um crescimento de $210 \%$, é bastante modesta em relação aos dos acadêmicos. Esse resultado é coerente com o próprio perfil finalístico do curso, já que os egressos de programas profissionais têm por objetivo a inserção imediata no mercado de trabalho, enquanto os acadêmicos têm maior propensão a desenvolver a carreira acadêmica gerando produções de caráter científico, tais como artigos e livros.

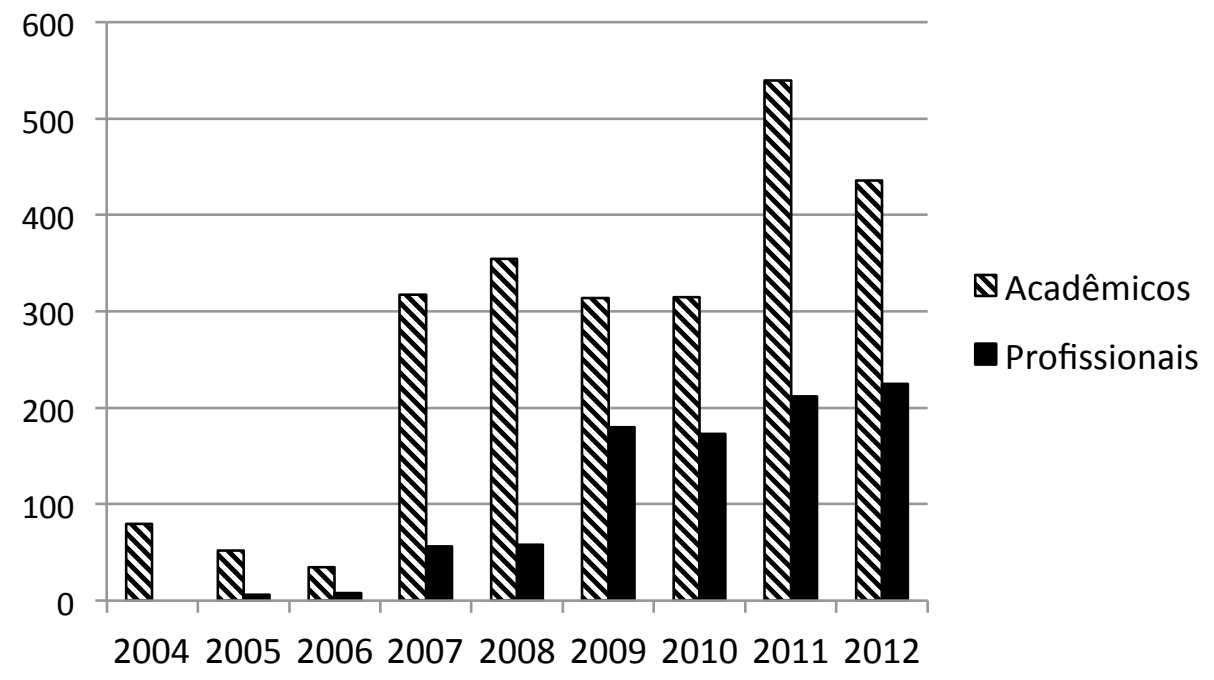

Figura 12. Número de produtos informados pelos alunos egressos titulados na área de Ensino distribuídos por modalidade do programa (Mestrado Profissional ou Mestrado Acadêmico e Doutorado), no período de 2004 a 2012. Fonte: SNPG/DAV/CAPES. 
Quanto ao tipo de publicação, notamos que o grande volume tanto da produção acadêmica quanto da profissional é de Artigos em Periódicos e de Livros e Capítulos, mas os programas profissionais se sobressaem isoladamente para as categorias de Serviços Técnicos e Desenvolvimento de Material Didático e Técnicas. Esse resultado é interessante, pois indica o fortalecimento do papel dos programas profissionais na formação de professores, uma vez que essas categorias de publicações refletem o trabalho prático dos alunos destes programas, ou seja, a atuação real em sala de aula dos professores em formação continuada.

\section{CONCLUSÃO}

A área de Ensino é, dentre as 48 áreas da CAPES, a que possui o maior número de programas de Mestrado Profissional, os quais estão distribuídos por todas as regiões do território nacional ainda que de forma não equilibrada. Esses programas são oferecidos principalmente por universidades federais, embora tenhamos constatado que o setor privado tem um papel muito importante na formação de mestres profissionais não só na área de Ensino, mas em todo o SNPG. O principal objetivo dos programas em Ensino é a formação de professores para atuar na mediação do conhecimento em espaços formais e não formais de ensino, integrando o conhecimento disciplinar com o conhecimento pedagógico.

Ensino vem recebendo anualmente um número cada vez maior de propostas de cursos novos, entre as quais predominam as propostas do tipo profissional. Especialmente após a instituição da Portaria CAPES/MEC no 17/2009 que regulamenta os MPs, houve um aumento na submissão de propostas dessa modalidade, o que demonstra a importância desse marco regulatório.

Analisando os índices de recomendação e os quesitos das fichas de avaliação das propostas de cursos novos, foi possível identificar os fatores que limitam sua recomendação. A grande fragilidade está na produtividade docente e consolidação da capacidade de pesquisa, mas também na própria adequação da proposta de curso, fatores estes que precisam ser fortalecidos dentro dos potenciais programas.

A Área tem um alto índice de recomendação de propostas, acima da média geral das áreas e vem crescendo em quantidade de programas e em qualidade expressa pelo aumento progressivo das notas nas Avaliações Trienais. Essa expansão é um indicativo da consolidação da identidade da área e da demanda por Pós-Graduação voltada para o aperfeiçoamento dos profissionais de ensino no país.

A despeito desse crescimento, a produtividade científica dos programas de MP ainda é inferior à dos acadêmicos, o que demonstra a necessidade da criação de indicadores específicos para essa modalidade e comprova o importante papel do fomento no desempenho dos programas. 


\section{REFERÊNCIAS}

1. Alves, C. G. M \& Del Pino, J. C. (2015, dezembro). A avaliação da pós-graduação stricto sensu no contexto dos Institutos Federais de Educação, Ciência e Tecnologia. Revista Eletrônica Debates em Educação Científica e Tecnológica, 05, (04), 21-64.

2. Barros, E. C.; Valentim, M. C. \& Melo, M. A. A. (2005, julho) O debate sobre o mestrado profissional na Capes: trajetória e definições. Revista Brasileira de Pós-Graduação, 2, (4), 124138.

3. Cevallos, I. \& Passos, L. F. (2012). O mestrado profissional e a pesquisa do professor. Revista Diálogo Educacional, 12, (37), 803-822.

4. Coordenação de Aperfeiçoamento de Pessoal de Nível Superior (2009). Documento da Área de Ensino de Ciências e Matemática - ano 2009. Brasília, DF. Recuperado em 10 de agosto, 2016, de http://www.capes.gov.br/component/content/article/44-avaliacao/4670-ensino

5. Coordenação de Aperfeiçoamento de Pessoal de Nível Superior (2013a). Documento da Área de Ensino - ano 2013. Brasília, DF. Recuperado em 10 de agosto, 2016, de http://www.capes.gov.br/component/content/article/44-avaliacao/4670-ensino

6. Coordenação de Aperfeiçoamento de Pessoal de Nível Superior (2013b). Relatório da Avaliação Trienal - ano 2013. Brasília, DF. Recuperado em 10 de agosto, 2016, de http://www.capes.gov.br/component/content/article/44-avaliacao/4670-ensino

7. Documento básico do programa de Apoio ao desenvolvimento científico e tecnológico e do subprograma Educação para a Ciência - SPEC/PADCT (1990, outubro). Brasil. Ministério de Ciência e Tecnologia. Recuperado em 14 de setembro, 2014, de www.cnpq.br

8. Feltes, H. P. M. \& Baltar, M. A. R. (2005, julho) Novas perspectivas para mestrados profissionais: competências profissionais e mercados regionais. Revista Brasileira de PósGraduação, 2 (4), 72-78.

9. Fischer, T. (2003). Seduções e riscos: a experiência do mestrado profissional. Revista de Administração de Empresas, 43, (2), 119-123.

10. Freitas, L. P.; Rodrigues, S. G. \& Costa, H. G. (2009). Emprego de abordagem multicritério para classificação do desempenho de instituições de ensino superior. Ensaio: Avaliação e Politicas Públicas em Educação, 17, (65), 655-674. https://dx.doi.org/10.1590/S0104-40362009000400006

11. Ludke, M. \& Cruz, G. B. (2005). Aproximando universidade e escola de educação básica pela pesquisa. Cadernos de Pesquisa, 35, (125), 81-109.

12. Moreira, C. O. F.; Hortale, V. A.; Hartz, Z. A. (2004, julho). A avaliação da Pós-graduação: buscando consenso. Revista Brasileira de Pós-Graduação, 1, 1, 26-40. 
13. Nepomuceno, L. D. O. \& Costa, H. G. (2012, janeiro). Mapeamento de percepções na avaliação dos impactos do mestrado profissional no perfil do seu egresso. Produção, 22, (4), 865873.

14. Oller, C.; Sotero, A.; Moreira, M. A.; Fischer, T.; Nicola, J. H. (2005, julho). Parâmetros para avaliação de mestrado profissional. Revista Brasileira de Pós-Graduação, 2, (4), 151-155.

15. Parecer CFE n. 977, de 3 de dezembro de 1965. Definição dos Cursos de Pós-Graduação, 1965. Brasília, DF. Recuperado em 05 agosto, 2016, de http://www.scielo.br/scielo.php?script=sci_arttext\&pid=S1413-24782005000300014

16. Portaria CAPES no 47, de 17 de outubro de 1995. Determina a implantação na Capes de procedimentos apropriados à recomendação, acompanhamento e avaliação de cursos de mestrado dirigidos à formação profissional. Brasília, DF. Recuperado em 08 de setembro, 2016, de http://ojs.rbpg.capes.gov.br/index.php/rbpg/article/view/87/83

17. Portaria CAPES no 80, de 16 de dezembro de 1998. Dispõe sobre o reconhecimento dos mestrados profissionais e dá outras providências. Brasília, DF. Recuperado em 08 de setembro, 2016, de https://www.capes.gov.br/images/stories/download/avaliacao/avaliacao-n/1892015Portaria-CAPES-080-1998.pdf

18. Portaria Normativa MEC no 17, de 28 de dezembro de 2009. Dispõe sobre o mestrado profissional no âmbito da Fundação Coordenação de Aperfeiçoamento de Pessoal de Nível Superior - CAPES. Brasília, DF. Recuperado em 10 de agosto, 2016, de http://capes.gov.br/images/stories/down load/avaliacao/avaliacao-n/Portaria-MEC-17-2009.pdf

19. Portaria CAPES no 83, de 6 de junho de 2011. Cria áreas do conhecimento. Brasília, DF. Recuperado em 08 de setembro, 2016, de https://www.capes.gov.br/images/stories/download/avaliacao/avaliacao-n/Portaria-capes-832011.pdf

20. Ribeiro, R. J. (2005, julho). O mestrado profissional na política atual da Capes. Revista Brasileira de Pós-Graduação, 2, (4), 8-15.

21. Ribeiro, T. A. \& Costa, H. G. (2005). Aplicação do método ELECTRE TRI à classificação da percepção do desempenho de IES por parte do corpo discente. XXV Encontro Nacional de Engenharia de Produção. Porto Alegre: ABEPRO. 1607-1614.

22. Richardson, R. J. (1989). Pesquisa social: métodos e técnicas. São Paulo: Atlas.

23. Rocha, N. M. F. (2006). Auto-avaliação de centros de Pós-Graduação: uma proposta em ação. Ensaio: Avaliação e Políticas Públicas em Educação, 14, (53), 487-506.

24. Vergara, S. C. (2005). Métodos de pesquisa em administração. São Paulo: Atlas. 